\title{
Artificial Inteligence Dalam Apilkasi Chatbot Sebagai Helpdesk Obyek Wisata Dengan Permodelan Natural Language Processing (Studi Kasus: Kabupaten Cilacap)
}

\author{
Mukrodin $^{1}$, Nurul Mega Sasmita ${ }^{2}$ \\ Email: ${ }^{1}$ mukrodins@gmail.com, ${ }^{2}$ nurul.mega.s@gmail.com \\ ${ }^{1}$ Program Studi Sistem Informasi, Universitas Peradaban \\ ${ }^{2}$ Program Studi Teknik Informatika, Universitas Peradaban \\ Jl. Raya Pagojengan KM 03 Paguyangan Brebes 52276 Jawa Tengah
}

\begin{abstract}
Abstrak
Perkembangan teknologi informasi berbasis komputer yang sangat cepat telah membuat banyak perubahan dalam sendi kehidupan manusia. Salah satu perkembangan teknologi terkini adalah kecerdasan buatan (artificial intelligence). Dengan adanya kecerdasan buatan, komputer dapat melakukan tugas tertentu seperti yang dilakukan oleh manusia robot chatting (chatbot). Chatbot adalah program komputer yang dapat melakukan percakapan melalui tulisan. Dalam era globalisasi sekarang ini, aspek kehidupan sehari-hari tak pernah lepas dari penggunaan teknologi informasi, salah satunya dalam aspek pariwisata. Pariwisata yang ada di Kabupaten Cilacap memiliki potensi yang banyak dikunjungi wisatawan. Namun pengembangan informasi pariwisata yang ada dirasa kurang efektif dan akurat. Dalam penyampaian informasi masih manual, yaitu dari informasi yang di dengar melalui orang lain. Karena itu, peneliti mencoba mengembangkan aplikasi chatbot sebagai helpdesk dengan pendekatan Natural Language Processing. Dengan aplikasi ini nantinya wisatawan mampu melakukan tanya jawab kepada sistem. Aplikasi ini menggunakan bahasa yang digunakan sehari-hari untuk manusia berkomunikasi.
\end{abstract}

Kata kunci : artificial intelligence, chatbot, helpdesk, Natural Language Processing.

\section{Pendahuluan}

Teknologi informasi terdiri atas dua kata yang memiliki makna berbeda. Kata teknologi berasal dari dua kata, yaitu techno yang berarti seni, dan logia (logos) yang berarti ilmu, teori. Sedangkan kata informasi berasal dari kata Perancis kuno pada tahun 1387, yaitu informacion yang diambil dari bahasa latin infomationem yang berarti garis besar, konsep, ide. Informasi merupakan kata benda dari informare yang berarti aktivitas dalam pengetahuan yang dikomunikasikan. Berdasarkan pendekatan tersebut maka teknologi informasi didefinisikan sebagai seni dan ilmu dalam menyampaikan informasi dari pengirim ke penerima (Dhewanto \& Anggadwita, 2015).

Perkembangan teknologi informasi berbasis komputer yang sangat cepat telah membuat banyak perubahan dalam sendi kehidupan manusia. Salah satu perkembangan teknologi terkini adalah kecerdasan buatan (artificial intelligence). Dengan adanya kecerdasan buatan, komputer dapat melakukan tugas tertentu seperti yang dilakukan oleh manusia robot chatting (chatbot). Secara garis besar, chatbot dapat melakukan tugas-tugas seperti melayani percakapan (chatting) dengan siapapun, seperti menyapa, menjawab, dan juga melayani permintaan dari orang lain (Enterprise, 2018).

Chatbot berperan sebagai agen percakapan yang dapat digunakan sebagai helpdesk. Helpdesk merupakan struktur atau program yang menangani segala bentuk keluhan dari berbagai pihak dengan menyediakan layanan untuk memberi informasi dan memberikan solusi kepada user.

Keberhasilan pengembangan pariwisata tidaklah hanya tergantung pada berapa banyak objek wisata yang dimiliki, keindahan, kealamian dan keunikan budaya dan tradisi masyarakat disekitar objek atau kawasan wisata namun yang jauh lebih penting adalah sumber daya manusia sebagai pengelola, sistem manajemen pengelolaan pariwisata dan informasi pariwisata itu sendiri. Kabupaten Cilacap merupakan salah satu kabupaten di Jawa Tengah yang memilik berbagai obyek wisata yang menarik.

Salah satu faktor yang menghambat perkembangan suatu pariwisata adalah pola promosi dan sistem pengelolaan informasi pariwisata yang belum baik sehingga terkadang objek wisata menjadi tidak dikenal dan tentunya tidak menjadi objek tujuan para 
wisatawan untuk berwisata. Informasi mengenai obyek wisata yang ada di Kabupaten Cilacap di dapat wisatawan berasal dari berbagai macam media sosial seperti facebook, instagram, twitter, dan mesin pencari seperti Google. Namun, informasi yang didapat oleh wisatawan tidak mampu mencakup seluruh wisata yang ada di Kabupaten Cilacap. Sehingga wisatawan hanya mampu memperoleh informasi hanya berdasarkan yang sudah ada di media sosial. Padahal masih banyak obyek wisata yang menarik dan belum terdapat di internet atau sosial media manapun.

Berdasarkan uraian di atas, penulis ingin membuat sebuah aplikasi yang dapat digunakan sebagai helpdesk. Dalam peneltian ini akan dibangun sebuah aplikasi chatbot sebagai helpdesk yang dapat membantu pengguna dalam memperoleh informasi yang tepat dan akurat secara efisien di website obyek wisata Kabupaten Cilacap. Pengguna dapat melakukan percakapan seperti kepada manusia dan sistem akan menjawab otomatis dengan kata kunci yang telah disediakan.

\section{Metodologi Penelitian}

\subsection{Tempat Penelitian}

Tempat yang di butuhkan untuk memperoleh data dalam penelitian ini adalah di seluruh daerah wisata yang ada di Kabupaten Cilacap.

2.2 Tahapan Penelitian

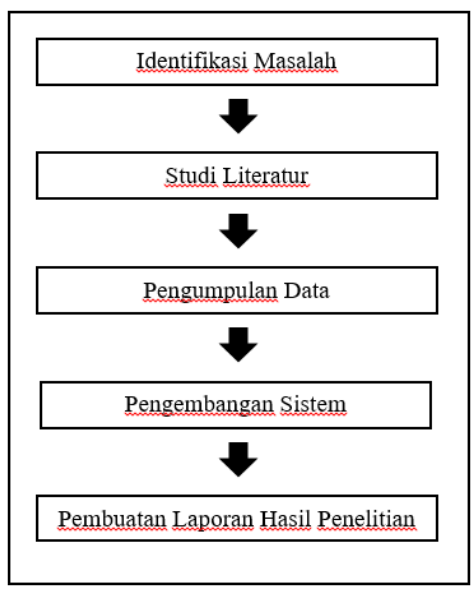

Bagan 1. Tahapan Penelitian

Tahapan dalam penilitian ini ada 5 (lima), yaitu:

2.2.1. Identifikasi Masalah

Pada tahap mengidentifikasi masalah dimaksudkan agar dapat memahami masalah yang akan diteliti, sehingga dalam tahap analisis dan perancangan tidak keluar dari permasalahan yang diteliti.

\subsubsection{Studi Literatur}

Pada tahap studi literatur penulis mempelajari dan memahami teori-teori yang menjadi pedoman danreferensi yang diperoleh dari berbagai buku, jurnal dan juga internet untuk melengkapi pembendaharaan konsep dan teori, sehingga memiliki landasan dan keilmuan yang baik guna menyelesaikan masalah yang di bahas dalam penelitian ini dan mempelajari penelitian yang relevan dengan masalah yang diteliti.

\subsubsection{Pengumpulan Data}

Sebelum

melakukan rancangan penelitian maka harus dicari data untuk kebutuhan penelitian. Data yang akan digunakan ada dua macam, yaitu:

1. Data primer: pada penelitian ini data primer yang digunakan adalah semua data yang telah digunakan pada penelitian sebelumnya.

2. Data sekunder : dalam penelitian ini diambil dari studi pustaka, literatur, maupun internet untuk mendapatkan informasi yang berkaitan dengan sistem ini.

\subsubsection{Perancangan Sistem}

Pada tahap ini penulis akan merancang usulan sistem yang baru, penulis menggunakan metode perancangan sistem dengan model Waterfall. Menurut Pressman (2010) (Roger S. Pressmas, 2001),

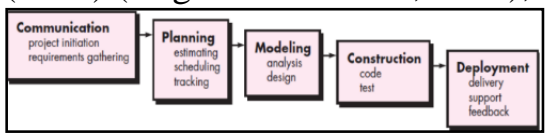

Bagan 2. Model Proses Waterfall

1. Communication (Komunikasi) Langkah ini merupakan analisis terhadap kebutuhan 
software, dan tahap untuk mengadakan pengumpulan data dengan melakukan pertemuan dengan customer, maupun mengumpulkan data-data tambahan baik yang ada di jurnal, artikel, maupun dari internet.

2. Planning (Perencanaan)

Proses planning merupakan lanjutan dari proses communication (analysis requirement). Tahapan ini akan menghasilkan dokumen user requirement atau bisa dikatakan sebagai data yang berhubungan dengan keinginan user dalam pembuatan software, termasuk rencana yang akan dilakukan.

3. Modeling (Pemodelan)

Proses modeling ini akan menerjemahkan syarat kebutuhan ke sebuah perancangan software yang dapat diperkirakan sebelum dibuat coding. Proses ini berfokus pada rancangan struktur data, arsitektur software, representasi interface, dan detail (algoritma) prosedural. Tahapan ini akan menghasilkan dokumen yang disebut software requirement.

4. Construction (Konstruksi)

Construction merupakan proses membuat kode (coding). Coding atau pengkodean merupakan penerjemahan desain dalam bahasa yang bisa dikenali oleh komputer. Programmer akan menerjemahkan transaksi yang diminta oleh user. Tahapan inilah yang merupakan tahapan secara nyata dalam mengerjakan suatu software, artinya penggunaan komputer akan dimaksimalkan dalam tahapan ini. Setelah pengkodean selesai maka akan dilakukan testing terhadap sistem yang telah dibuat tadi. Tujuan testing adalah menemukan kesalahankesalahan terhadap sistem tersebut untuk kemudian bisa diperbaiki.

5. Deployment (Penyerahan)

Tahapan ini bisa dikatakan final dalam pembuatan sebuah software atau sistem. Setelah melakukan analisis, desain dan pengkodean maka sistem yang sudah jadi akan digunakan oleh user. Kemudian software yang telah dibuat harus evaluasi jika ada kekurangan dan dilakukan pemeliharaan secara berkala.

\subsubsection{Pembuatan Laporan Hasil}

Penelitian

Pada tahap ini, penulis membuat laporan dari penelitian yang berisikan laporan penelitian terhadap masalah-masalah dan solusi yang ada pada objek yang diteliti oleh peneliti yaitu Artificial Intelligence dalam Aplikasi Chatbot sebagai Helpdesk Objek Wisata Dengan Permodelan Natural Language Processing (Studi Kasus: Kabupaten Cilacap).

\section{Hasil dan Pembahasan}

Analisa sistem pada aplikasi chatbot website Wisata Kabupaten Cilacap yang dirancang terdiri dari analisa kebutuhan data dan analisa kebutuhan proses. Analisis dilakukan dengan tujuan untuk mengidentifikasi dan mengevaluasi seluruh komponen yang terkait dengan sistem yang akan dibangun. Tahap analisis sistem dilakukan dengan cara menguraikan suatu sistem yang utuh kedalam bagian-bagian komponennya dengan maksud untuk mengidentifikasi dan mengevaluasi permasalahan-permasalahan sehingga ditemukan kelemahan dan keuntungan pada sistem tersebut.

Berdasarkan permasalahan di atas, diharapkan dapat diselesaikannya sebuah aplikasi chatbot yang menggunakan metode Natural Language Processing (NLP) sudah cocok untuk diimplementasikan pada aplikasi chatbot.

Analisis kebutuhan sistem non fungsional adalah sebuah langkah dimana seorang pembangun perangkat lunak menganalisis sumber daya manusia yang akan menggunakan perangkat lunak yang dibangun. 
Dalam aplikasi chatbot yang akan dikembangkan, user mendaftarkan e-mail mereka untuk melakukan layanan chatting dalam chatbox yang sudah disediakan. User memasukkan kata yang ingin dicari jawabannya, maka chatbot akan menjawab apa yang ditanyakan user. Base knowldge yang disediakan oleh chatbot adalah seputar informasi wisata yang ada di Kabupaten Cilacap.

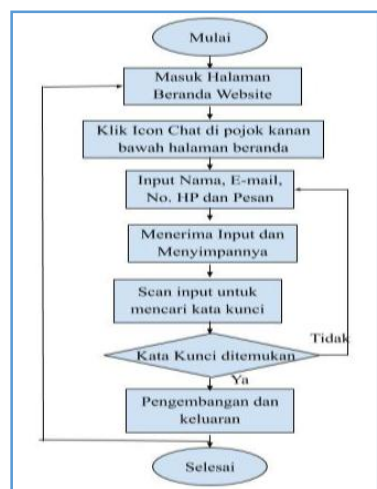

Gambar 1 Gambaran Umum Sistem

Deskripsi:

1. User masuk ke Halaman Beranda website wisata Kabupaten Cilacap.

2. User mengklik icon chat yang ada di pojok kanan bawah Halaman Beranda.

3. User meng-input-kan Nama, E-mail, No. $\mathrm{Hp}$, dan Pesan (kata/kalimat) yang ingin ditanyakan kepada chatbot.

4. Kemudian chatbot menerima Pesan (kata/kalimat) kemudian menyimpannya ke dalam database chatbot.

5. Chatbot kemudian akan men-scan input untuk mencari kata kunci dalam database.

6. Apabila chatbot menemukan kata kunci yang dimaksud oleh user, maka chatbot akan mengelurakan jawaban Pesan dalam bentuk kalimat dan pengembangan dari Pesan.

7. Jika kata kunci tidak ditemukan, maka user akan diminta ulang untuk mengetikan kata kunci yang lain.

Penelitian ini mengembangkan sistem pengolah bahasa alami dengan bahasa Indonesia untuk mendapatkan data dan informasi dari database. Informasi yang didapatkan adalah data-data yang berkaitan dengan informasi wisata yang ada di Kabupaten Cilacap. Data informasi wisata diantaranya adalah lokasi, harga tiket, jam buka dan tutup, sarana dan prasarana obyek wisata, dan akomodasi.

Penelitian ini secara garis umumnya melakukan perancangan dan implementasi aplikasi yang menerjemahkan bahasa alami dengan bahasa Indonesia ke dalam bahasa $S Q L$ yang kemudian ditampil-kan dalam bentuk query.

Sistem yang dirancang hanya dapat menerima pertanyaan sesuai dengan aturan produksi yang ditetapkan di atas. Pertanyaan yang tidak sesuai dengan pola aturan di atas akan terjadi pesan kesalahan atau diabaikan.

Komponen bahasa alami dalam aplikasi chatbot tertera pada gambar di bawah ini. Sebelum mendapatkan hasil, maka setiap teks input akan melewati beberapa proses yaitu analisis leksikal, sintak, semantik, dan praagmantik (Utami \& Hartati, 2007).

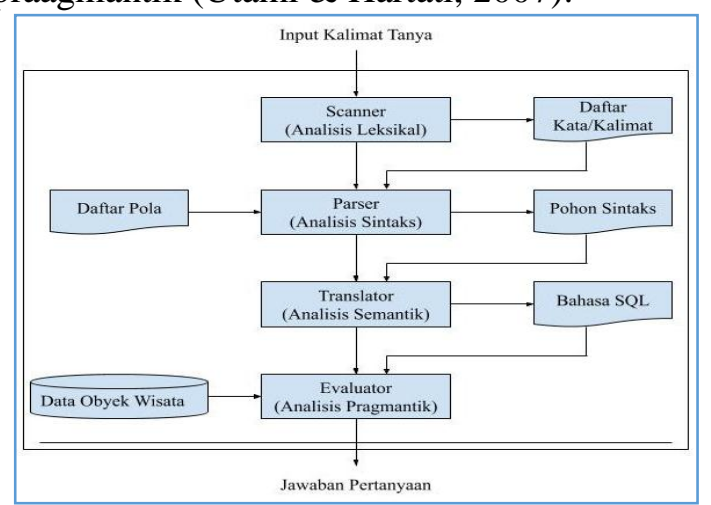

Gambar 2 Tahapan Pemrosesan Bahasa Alami dalam Aplikasi Chatbot

1. Scanner (Anailisis Leksikal)

Pemberian batasan pertanyaan dilakukan oleh sub sistem yang bernama scanner dan parser. Pemrosesan awal pertanyaan dilakukan oleh scanner yang akan membuat pertanyaan menjadi sebuah daftar token. Pada penelitian ini scanner melakukan 3 aktivitas yakni : menghilangkan tanda baca, memecah pertanyaan dan mengubah menjadi huruf kecil. Pada gambar di bawah menampilkan tahap analisis leksikal dengan contoh satu input.

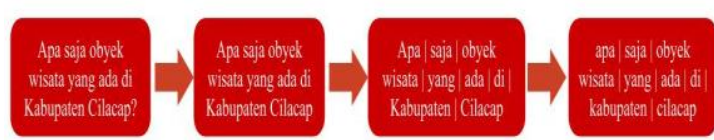

Gambar 3 Tahap Analisis Leksikal 
2. Parser (Analisis Sintaks)

Daftar token yang terbentuk akan dianalisa oleh parser apakah sesuai dengan pembentukan pola kalimat yang telah ditetapkan. Penentuan struktur kalimat bisa jadi merupakan pekerjaan yang sulit bergantung dari bahasa yang digunakan. Parsing morfologi merupakan kegiatan yang dilakukan untuk menentukan struktur kata. Pada penelitian ini secara umum parser akan melakukan:

a. Membaca daftar token

b. Membaca cacah token

c. Membaca isi token

d. Membandingkan dengan aturan produksi

Analisis sintaks melakukan pelacakan terhadap token-token yang dihasilkan oleh scanner kemudian dibandingkan dengan daftar token yang tersedia. Jika sesuai dengan daftar token yang ada maka dilihat apakah terdapat kecocokan dengan aturan produksi yang ada. Sebagai contoh gambar di bawah ini merupakan tahap analisis sintak dengan membaca isi token dalam termin obyek wisata apakah sesuai dengan daftar token yang diijinkan.

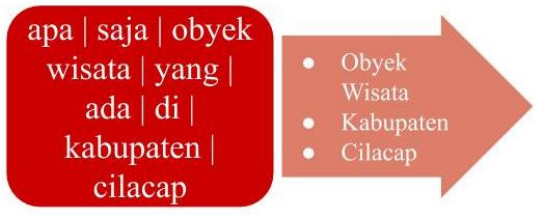

Gambar 4 Tahap Analisis Sintaks

\section{Translator (Analisis Semantik)}

Translator berfungsi untuk memetakan hasil parser yang sesuai dengan aturan produksi ke dalam bahasa hasil yakni bahasa query, sehingga yang dilakukan pada semantik meliputi:

a. Membaca hasil scanner

b. Memetakan ke dalam Bahasa Query

Pada tahap ini atribut dan obyek memegang peranan penting dalam translator. Sebagai contoh kalimat input " Apa saja obyek wisata yang ada di Kabupaten Cilacap?", maka dalam translator menjadi "obyek wisata kabupaten cilacap". Kalimat tersebut akan diterjemahkan ke dalam bahasa query menjadi "Select obyek from lokasi where = 'obyek lokasi cilacap"".

4. Modeling (Pemodelan)
Proses modeling ini akan menerjemahkan syarat kebutuhan ke sebuah perancangan software yang dapat diperkirakan sebelum dibuat coding. Proses ini berfokus pada rancangan struktur data, arsitektur software, representasi interface, dan detail (algoritma) prosedural. Tahapan ini akan menghasilkan dokumen yang disebut software requirement. Pada penelitian ini menggunakan Use Case Diagram untuk perancangan sistem berorientasi objek.

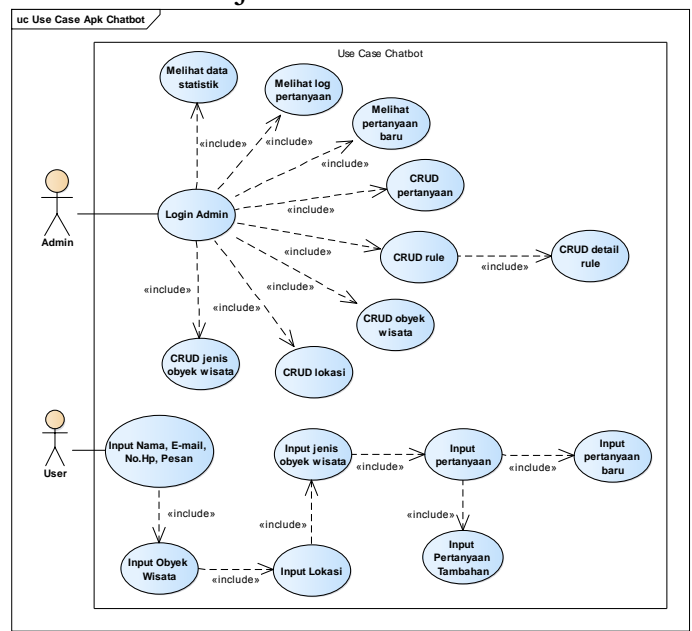

Gambar 5 UML Aplikasi Chatbot

Proses Bisnis Use Case Diagram Chatbot merupakan penjelasan dari apa yang dilakukan oleh aktor-aktor dan use case yang terlibat dalam perangkat lunak yang dibangun. Adapun aktor-aktor yang terlibat dalam aplikasi chatbot website wisata kabupaten Cilacap adalah sebagai berikut :

Tabel 1 Tabel Definisi Aktor Use Case Diagram Chatbot

\begin{tabular}{|c|c|c|}
\hline No & Aktor & Proses Bisnis \\
\hline 1. & User & $\begin{array}{l}\text { 1. User menginputkan } \\
\text { Nama, E-mail, No.Hp, } \\
\text { Pesan. Dimana dalam } \\
\text { menginput pesan terdiri } \\
\text { dari beberapa suku kata } \\
\text { yang di dalamnya } \\
\text { terdapat kata obyek } \\
\text { wisata, lokasi atau jenis } \\
\text { obyek wisata } \\
\text { 2. Setelah menginput Pesan } \\
\text { yang diinginkan, user } \\
\text { bisa menginputkan } \\
\text { pertanyaan tambahan dan } \\
\text { pertanyaan baru }\end{array}$ \\
\hline 2. & Admin & $\begin{array}{l}\text { 1. Admin dapat melihat data } \\
\text { statisik tentang segala } \\
\text { kegiatan yg terjadi dalam }\end{array}$ \\
\hline
\end{tabular}




\begin{tabular}{|c|c|c|}
\hline No & Aktor & Proses Bisnis \\
\hline & & $\begin{array}{l}\text { aplikasi chatbot } \\
\text { 2. Admin dapat melihat log } \\
\text { pertanyaan yg menjadi } \\
\text { basis data aplikasi } \\
\text { chatbot } \\
\text { 3. Admin dapat melihat } \\
\text { pertanyaan yang baru } \\
\text { masuk } \\
\text { 4. Admin dapat CRUD } \\
\text { (Create, Read, Update, } \\
\text { Delete) pertanyaan yang } \\
\text { menjadi basis data } \\
\text { 5. Admin dapat CRUD } \\
\text { (Create, Read, Update, } \\
\text { Delete) rule, dan detail } \\
\text { rule. Rule digunakan } \\
\text { untuk mencocokan pola } \\
\text { pertanyaan yang dikirim } \\
\text { oleh user dengan pola } \\
\text { kalimat yang sudah } \\
\text { disimpan dalam basis } \\
\text { data } \\
\text { 6. Admin dapat melakukan } \\
\text { CRUD (Create, Read, } \\
\text { Update, Delete) obyek } \\
\text { wisata } \\
\text { 7. Admin dapat melakukan } \\
\text { CRUD (Create, Read, } \\
\text { Update, Delete) l lokasi } \\
\text { obyek wisata } \\
\text { 8. Admin dapat melakukan } \\
\text { CRUD (Create, Read, } \\
\text { Update, Delete) jenis } \\
\text { obyek wisata }\end{array}$ \\
\hline
\end{tabular}

Activity Diagram saat user memberi pertanyaan pada aplikasi chtbot yang ada di website wisata Kabupaten Cilacap adalah sebagai berikut:

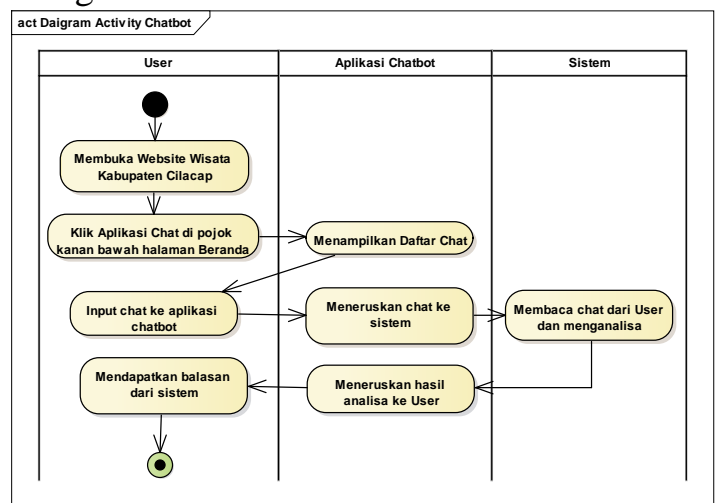

Gambar 6 Diagram Activity Chatbot

Gambar di atas menunjukan aktivitasaktivitas yang dapat dilakukan user pada sistem.
Langkah pertama aktor user membuka website wisata Kabupaten Cilacap. Kemudian pilih chatroom dengan meng-klik icon chat yang ada di sebelah pojok kanan bawah halaman beranda. Kemudian aplikasi akan menampilkan halaman chatting. Setelah user membuka aplikasi chat, aksi yang dilakukan user setelah data chat tampil adalah melakukan chat kepada aplikasi chat, pada aktor aplikasi chat dari user akan diteruskan aplikasi chatbot menuju sistem, pada aktor sistem akan membaca chat dari user dan diproses untuk langkah scanner, pasrser, dan translator. Dan setelah translator membaca hasil scanner dan memetakan ke dalam bahasa query maka balasan akan diterima oleh user.

Class diagram yaitu salah satu jenis diagram pada UML yang digunakan untuk menampilkan kelas-kelas maupun paket-paket yang ada pada suatu sistem yang nantinya akan digunakan. Jadi diagram ini dapat memberikan sebuah gambaran mengenai sistem maupun relasi-relasi yang terdapat pada sistem tersebut.

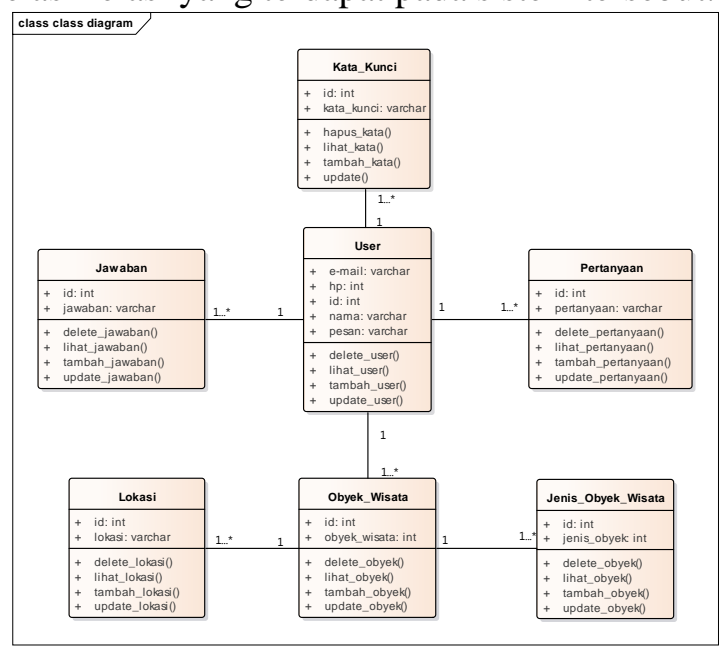

Gambar 7 Class Diagram Chatbot

Sequence diagram yaitu salah satu jenis diagram pada UML yang menjelaskan interaksi objek yang berdasarkan urutan waktu, sequence diagram juga dapat menggambarkan urutan atau tahapan yang harus dilakukan untuk dapat menghasilkan sesuatu seperti pada use case diagram 


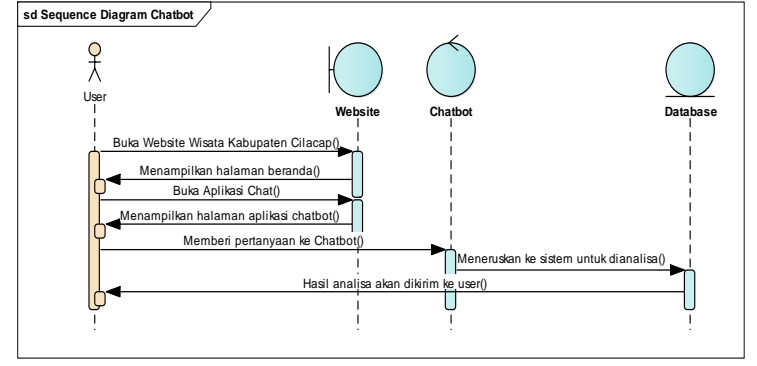

Gambar 8 Sequence Diagram Chatbot

1. Implementasi Halaman Chatbot
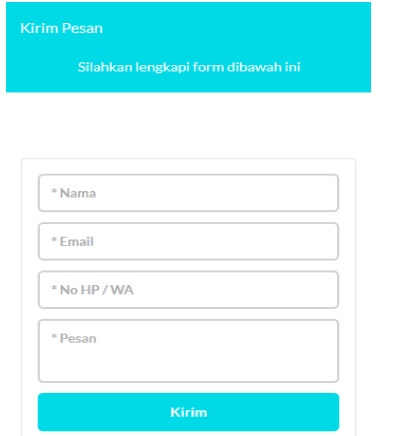

Gambar 9 Halaman Aplikasi Chatbot

\section{Implementasi Percakapan dengan Chatbot}

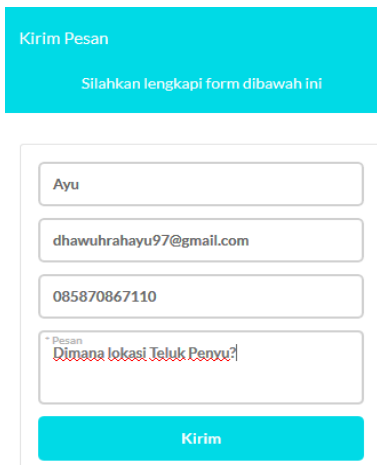

Gambar 10 Percakapan dengan Aplikasi

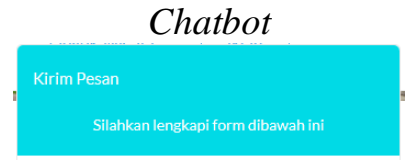

Pesan berhasil dikirim!

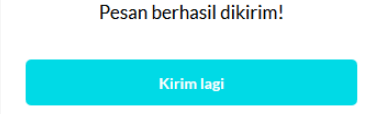

Gambar 11 Percakapan dengan Aplikasi Chatbot

Pengujian sistem merupakan hal terpenting yang bertujuan untuk menemukan kesalahan-kesaahan atau kekurangan- kekurangan pada perangkat lunak yang diuji. pengujian bermaksud untuk mengetahui perangkat lunak yang dibuat sudah memenuhi kriteria yang sesuai dengan tujuan perancangan perangkat lunak tersebut. Pengujian perangkat lunak ini menggunakan pengujian blackbox. Pengujian blackbox berfokus pada persyaratan fungsional perangkat lunak. Skenario pengujian menjelaskan terhadap sistem yang ada pada aplikasi chatbot menggunakan pendekatan Natural Language Processing. Skenario pengujian yang akan dilakukan pada aplikasi ini selengkapnya akan dilihat pada tabel berikut.

Tabel 2 Tabel Pengujian Sistem

\begin{tabular}{|c|c|c|c|}
\hline No. & $\begin{array}{c}\text { Pertanyaan } \\
\text { User }\end{array}$ & Jawaban Sistem & Status \\
\hline 1. & $\begin{array}{l}\text { Dimana } \\
\text { lokasi } \\
\text { obyek } \\
\text { wisata } \\
\text { Teluk } \\
\text { Penyu? }\end{array}$ & $\begin{array}{l}\text { Obyek Wisata } \\
\text { Teluk Penyu } \\
\text { berada } \\
\text { Pandanarang, } \\
\text { Cilacap Selatan, } \\
\text { Cilacap, Jawa } \\
\text { Tengah, } \\
\text { Indonesia. }\end{array}$ & $\sqrt{ }$ \\
\hline 2. & $\begin{array}{l}\text { Berapa } \\
\text { harga tiket } \\
\text { obyek } \\
\text { wisata } \\
\text { Teluk } \\
\text { Penyu? }\end{array}$ & $\begin{array}{lr}\text { Harga } & \text { tiket } \\
\text { obyek } & \text { wisata } \\
\text { Teluk } & \text { Penyu } \\
\text { adalah } & \text { Rp } \\
7.000,00 & \end{array}$ & $\sqrt{ }$ \\
\hline 3. & $\begin{array}{l}\text { Apa saja } \\
\text { fasilitas } \\
\text { yang ada } \\
\text { di obyek } \\
\text { wisata } \\
\text { Teluk } \\
\text { Penyu? }\end{array}$ & $\begin{array}{l}\text { Terdapat fasilitas } \\
\text { yang cukup } \\
\text { lengkap di } \\
\text { kawasan wisata } \\
\text { Pantai Teluk } \\
\text { Penyu di } \\
\text { Cilacap ini } \\
\text { diantaranya } \\
\text { kamar } \\
\text { mandi/toilet, } \\
\text { mushola, parkir, } \\
\text { gazebo, } \\
\text { mercusuar, } \\
\text { lapangan voli, } \\
\text { water sport, } \\
\text { perahu } \\
\text { penyeberangan } \\
\text { ke } \\
\text { Nusakambangan, } \\
\text { trackdam, kolam } \\
\text { pemancingan, } \\
\text { kios buah, kios } \\
\text { oleh - oleh, kios } \\
\text { cederamata dan } \\
\text { lainnya. }\end{array}$ & $\sqrt{ }$ \\
\hline
\end{tabular}




\begin{tabular}{|c|l|l|c|}
\hline No. & $\begin{array}{l}\text { Pertanyaan } \\
\text { User }\end{array}$ & Jawaban Sistem & Status \\
\hline 4. & $\begin{array}{l}\text { Obyek } \\
\text { Wisata } \\
\text { Teluk } \\
\begin{array}{l}\text { Penyu } \\
\text { buka jam } \\
\text { berapa? }\end{array}\end{array}$ & $\begin{array}{l}\text { Jam operasional } \\
\text { adalah setiap } \\
\text { hari 24 Jam }\end{array}$ & $\sqrt{ }$ \\
\end{tabular}

Tahapan terakhir yaitu penyerahan sistem kepada pengurus pariwisata Kabupaten Cilacap. Dengan melalui proses beberapa tahapan sebelumnya, seperti komunikasi atau wawancara kepada beberapa pengelola wisata di Kabupaten Cilacap, pengambilan data, dan melakukan beberapa tahap penngujian. Pada tahap penyerahan, peneliti melakukan penyerahan sistem Artificial Intelligence dalam Aplikasi Chatbot sebagai Helpdesk Obyek Wisata dengan Permodelan Natural Language Processing (Studi Kasus: Kabupaten Cilacap) ke objek penelitian yaitu Kabupaten Cilacap.

Penelitian beserta pengembangan sistem sudah selesai dilakukan sesuai dengan yang direncanakan. Seluruh tahapan pengambangan sistem juga sudah berhasil dibangun hingga pengujian sistemnya. Capaian yang menjadi target penelitian pun berhasil diperoleh. Untuk selanjutnya, hasil penelitian akan dipublikasikan dalam jurnal terkait. Dari penelitian ini, selanjutnya dapat dijadikan sebagai bahan rujukan pengabdian kepada masyarakat terkait dengan penggunaan aplikasi chatbot dalam website wisata Kabupaten Cilacap.

\section{Kesimpulan}

Berdasarkan hasil implementasi dan pengujian yang telah dilakukan pada aplikasi chatbot dengan pendekatan Natural Language Processingini maka dapat diambil kesimpulan bahwa pembangunan chatbot dengan pendekatan Natural Language Processing merupakan pendekatan yang yang baik untuk diterapkan dalam sistem chatbot karena user dapat melakukan percakapan seperti kepada sesama manusia dengan proses pencarian kata kunci yang terbukti dalam pengujian blackbox. Dari hasil penelitian tersebut penulis menyimpulkan bahwa aplikasi ini sangat membantu user dalam proses pencarian informasi.

\section{DAFTAR PUSTAKA}

[1] Bahartyan, E., Bahtiar, N., \& Waspda, I. (t.thn.). Integrasi Chatbot Berbasis AIML pada Website E-Commerce sebagai Virtual Assistant dalam Pencarian dan Pemesanan Produk (Studi Kasus Toko Buku Online edua4indo.com). Jurnal Masyarakat Informatika, 5(10), 34-43.

[2] Csaky, R. K. (2017). Deep Learning Based Chatbot Models.

[3] Dhewanto, W., \& Anggadwita, G. (2015). Rencana Pengembangan Teknologi Informasi Tahun 2015-2019. PT. Republik Solusi.

[4] Enterprise, J. (2018). Teknik Memasang Chatbot di Toko Online. Jakarta: PT Elex Media Komputindo.

[5] Hartati, S., \& Zuliarso, E. (2008). Aplikasi Pengolah Bahasa Alami untuk Query Basisdata XML. Jurnal Informasi DINAMIK, XIII(2), 168-175.

[6] Hormansyah, D. S., \& Utama, Y. P. (2018). Aplikasi Chatbot Berbasis Web Pada Sistem Informasi Layanan Kesehatan di Malang dengan Menggunakan Metode TFIDF. Jurnal Informatika Polinema, 4(3), 224-228.

[7] Kusumadewi, S. (2003). Artificial Intelligence (Teknik dan Aplikasinya). Yogyakarta: Graha Ilmu.

[8] Rakhman, A. (2020). Patient Medical Record Information System as Big Data Implementation with NIK in Tegal City Health Service. Jurnal Mantik, 4(3), 20562062.

[9] Kusuma, A. C., \& Rakhman, A. (2017). Peningkatan Keterampilan Olah Data (SPSS) Pada Mahasiswa DIII Akuntansi Politeknik Harapan Bersama Tegal. Jurnal Abdimas PHB: Jurnal Pengabdian Masyarakat Progresif Humanis Brainstorming, 1(1), 49-54.

[10] Roger S. Pressmas, P. (2001). Software Engineering A Practicioner's Approach. New York: The McGraw-Hill CompaniesInc.

[11] Russel, S. J., \& Norvig, P. (2010). Artificial Intelligence A Modern Approach Third Edition. United States of America: Pearson Education,Inc.

[12] Utami, E., \& Hartati, S. (2007). Pendekatan Metode Rule Based dalam Mengalihbahasakan Teks Bahasa Inggris ke Teks Bahasa Indonesia. Jurnal Informatika, $8(1)$. 